\title{
Xenon Capture on Silver-Loaded Zeolites: Characterization of Very Strong Adsorption Sites
}

\author{
Cécile Daniel, ${ }^{\dagger}$ Adnane Elbaraoui, ${ }^{\dagger}$ Sonia Aguado, ${ }^{\dagger}$ Marie-Anne Springuel-Huet, ${ }^{\ddagger}$ \\ Andrei Nossov, ${ }^{\ddagger}$ Jean-Pierre Fontaine, ${ }^{\S}$ Sylvain Topin, ${ }^{\S}$ Thomas Taffary, ${ }^{\S}$ Ludovic Deliere, ${ }^{\S}$ \\ Yves Schuurman, ${ }^{\dagger}$ and David Farrusseng ${ }^{*}{ }^{\dagger}$ \\ ${ }^{\dagger}$ IRCELYON, Université Lyon-1, CNRS, -2, Avenue Albert Einstein, F-69626 Villeurbanne, France \\ ${ }^{\ddagger}$ UMR 7574, Chimie de la Matière Condensée de Paris, UPMC Universite Paris 06 and CNRS, F-75005 Paris, France \\ ${ }^{\S}$ Commissariat à l'Energie Atomique (CEA), DAM, DIF, F-91297 Arpajon, France
}

\begin{abstract}
The number and strength of adsorption sites for Xe in silver-modified zeolites are estimated from isotherm measurements at various temperatures over a broad range of pressure (from 1 ppm to atmospheric pressure). Fully and partially exchanged silver zeolites were synthesized starting from Na-ZSM-5(25), Na-ZSM-5(40), Na-Beta, NaX, and NaY. We have discovered that silver-modified zeolites may present one or two distinct adsorption sites depending on the nature of the material and silver loadings. The strongest adsorption sites are characterized by isosteric heat of adsorption in the order of -40 to $-50 \mathrm{~kJ} \cdot \mathrm{mol}^{-1}$. For Pentasil-type zeolites, we observe a linear 2:1 correlation between the total amount of silver and the number of strong sites. The highest concentration of strong sites is found for fully silver exchanged ZSM-5 (5.7 $\times 10-4$ mol/ $\mathrm{g}$ ), which presents the largest silver content for Pentasil-type zeolite. The equilibrium constant of Ag-ZSM-5 at low pressure is about 50 times larger than that of AgX. Qualitative correlations were established between Xe adsorption isotherms and Xe NMR signals. We show that Xe NMR could be used as a quantitative method for the characterization of the strength and of the number of strong Xe adsorption sites on silver-exchanged zeolites. The numbers of strong adsorption sites responsible for the Xe adsorption at 10-1000 ppm can be determined by the length of the plateau observed at low Xe uptake. In practice, our findings give guidelines for the discovery and optimization of silver-loaded zeolites for the capture of Xe at ppm levels. It appears that the amount of silver is a key parameter. Silver-modified ZSM-5 shows adsorption capacities 2-3 orders of magnitude larger than currently applied adsorbents for atmospheric Xe capture.
\end{abstract}

\section{INTRODUCTION}

At large, xenon is currently extracted from air by distillation. Most of the xenon produced in the world is used in specialized lighting. ${ }^{1}$ Xenon might find widespread application as an anesthetic gas, having been referred to as ideal, but its current high price prevents widespread usage. ${ }^{2}$ The monitoring of radioactive xenon isotopes (radioxenons) in the atmosphere is continuously performed at different places worldwide in application of the verification regime of the Comprehensive Nuclear Test Ban Treaty (CTBT) ${ }^{2-7}$ In a nuclear explosion, four radioactive xenon isotopes are produced in significant amounts with halflives long enough for them to be detected even several days after the explosion: ${ }^{131 \mathrm{~m}} \mathrm{Xe}\left(t_{1 / 2}=11: 84 \mathrm{~d}\right),{ }^{133} \mathrm{Xe}\left(t_{1 / 2}=5: 243 \mathrm{~d}\right)$, ${ }^{133 \mathrm{~m}} \mathrm{Xe}\left(t_{1 / 2}=2: 19 \mathrm{~d}\right),{ }^{135} \mathrm{Xe}\left(t_{1 / 2}=9: 14 \mathrm{~h}\right)$. The measurement of xenon isotopes amount and proportion allows discriminating a nuclear test from other sources, such as fuel reprocessing and in hospitals where they are used for diagnostic applications. Several monitoring units which contain Temperature Swing Adsorption (TSA) processes were developed. The devices extract and concentrate xenon from ambient air for allowing on site measurements of atmospheric activities of radioxenon isotopes. ${ }^{8}$ Because of the very low concentration level of Xe in the atmosphere $(0.087 \mathrm{ppm})$, staged adsorbent processes are required. The development of adsorbents with heat of adsorption larger than state of the art carbon-based materials will result in the shortening of the separation chain and process intensification.

High-pressure Xe adsorption isotherms for xenon in various zeolites were reported many years ago by Barrer and coworkers. $^{9-11}$ More recently, the temperature dependence of xenon adsorption isotherms at low pressures of xenon has been described for zeolite $5 \mathrm{~A},{ }^{12}$ zeolite $\mathrm{Y}^{13}$ and chabazite, SAPO-34, and ALPO-CHA. ${ }^{14}$ The zeolite Ca- and $\mathrm{K}$-chabazites were found to adsorb Xe the strongest with enthalpies of adsorption in the range of $-40 \mathrm{~kJ} \cdot \mathrm{mol}^{-1}$.9,14

In the early 1970s, Xe was found to exhibit outstandingly strong interaction with silver-exchanged zeolites. ${ }^{10}$ Silver-exchanged 
faujasites have been the most studied systems. ${ }^{13,15-19}$ At low pressure, $\mathrm{Xe}$ is adsorbed more strongly in the silver-exchanged $\mathrm{X}$ and $\mathrm{Y}$ zeolites than in their sodium counterparts. In $\mathrm{Y}$ zeolite, the isosteric heats of adsorption of xenon on Ag-exchanged and $\mathrm{NaY}$ materials were -31.0 and $-18.5 \mathrm{~kJ} \cdot \mathrm{mol}^{-1}$, respectively. ${ }^{13}$ More recently, the beneficial effect of silver loading was also observed on other zeolites, Ag-exchanged mordenite, ${ }^{20}$ ETS-10, ${ }^{21}$ chabazite, ${ }^{22}$ and ZSM- $5 .{ }^{23}$ Highest isosteric heat of adsorption values between -40 and $-95 \mathrm{~kJ} \cdot \mathrm{mol}^{-1}$ were reported on Ag-ETS-10, although the latter values were not reproduced by chromatographic measurements. The strong adsorption on silver-loaded ETS-10 zeolite was attributed by the authors to a specific interaction of xenon with silver nanoparticles $\left(\mathrm{Ag}^{\circ}\right)$ in the ETS-10. ${ }^{21}$ On the basis of Xe NMR investigations, Gedeon et al. ${ }^{17,20}$ have suggested, on the contrary, that cationic $\mathrm{Ag}^{+}$clusters may be responsible for the strongest interaction with $\mathrm{Xe}$ whereas $\mathrm{Ag}^{\circ}$ particles may not. ${ }^{16}$ Theoretical studies at DFT level on silver clusters in the gas phase and silver-exchanged chabazite zeolites demonstrate that strong adsorption occurs on silver cluster cations and not significantly on neutral silver particles. ${ }^{22}$ The authors conclude that the strong binding originates from $\sigma$ donation from the $5 \mathrm{p}$ orbital of $\mathrm{Xe}$ to the $5 \mathrm{~s}$ orbital of $\mathrm{Ag}$ in contrast to previous assumption suggesting $\mathrm{d} \pi-\mathrm{d} \pi$ back-donation. However, we can note major discrepancies between theoretical binding energy as computed for Ag-chabazite $\left(14 \mathrm{~kJ} \cdot \mathrm{mol}^{-1}\right)$ and experimental heat of adsorption at zero coverage for $\operatorname{AgY}\left(-31 \mathrm{~kJ} \cdot \mathrm{mol}^{-1}\right){ }^{13,22}$

As a matter of fact, the debate of the strength and nature of adsorption sites in silver exchanged zeolites is still open. Similarly, the negative Xe NMR chemical shifts in $\mathrm{AgX}$ and $\mathrm{AgY}$ zeolites remain a puzzle. ${ }^{16-19,24-28}$ The effects of porous structure of the zeolite and silver loading on adsorption properties are largely unknown. Furthermore, experimental values of isosteric heat of adsorption may not be appropriate for the comparison with theoretical values computed at zero coverage, and also for the prediction of adsorption capacities at ppm level of Xe. Indeed measurements have been carried out in the Xe pressure range $1-100 \mathrm{kPa}$ exceeding by orders of magnitude the $\mathrm{Xe}$ partial pressure in the atmosphere $\left(\sim 0.1 \mathrm{ppm}=10^{-5} \mathrm{kPa}\right)$.

This paper deals with the characterization of adsorption sites meaning the quantification of their number and strength for a series of partially and completely silver exchanged zeolites, $\mathrm{NaX}$, NaY, BEA, ZSM-5 $\left(\mathrm{SiO}_{2} / \mathrm{Al}_{2} \mathrm{O}_{3}=25\right)$, and ZSM-5 $\left(\mathrm{SiO}_{2} / \mathrm{Al}_{2} \mathrm{O}_{3}=\right.$ 40). The modeling of isotherms allows discriminating two types of adsorption sites depending on the nature of zeolites (pentasil versus faujasite) and silver loading. For Pentasil-type zeolite (BEA, MFI), we show a linear correlation between the amount of silver and the number of strong adsorption sites. We further show that the Xe NMR signals characterized by unusual negative shift can be associated with the strong adsorption site, responsible for Xe adsorption between 1 and 1000 ppm.

\section{EXPERIMENTAL SECTION}

Adsorbents were prepared from five commercially available zeolites (Table 1). The silicon to aluminum ratio effect on the adsorption performances is studied for two types of zeolite structures, FAU and MFI. Additionally, exchanged Beta zeolites which show Pentasil secondary building block units (SBU) like MFI have been studied.

Silver was loaded using the classical exchange procedure starting with sodium zeolite forms. In order to investigate the effect of silver loading on adsorption performances, partially and completely exchanged samples have been prepared. The
Table 1. Data on Commercial Zeolite Materials

\begin{tabular}{|c|c|c|c|c|c|}
\hline zeolite & supplier & reference & structure & $\begin{array}{l}\mathrm{SiO}_{2} / \\
\mathrm{Al}_{2} \mathrm{O}_{3}\end{array}$ & $\mathrm{Na}(\% w t)$ \\
\hline $\mathrm{NaX}$ & UOP & $13 \mathrm{X}$ & FAU & 1.1 & 9.7 \\
\hline $\mathrm{NaY}$ & Toyo Soda & HSZ320NAA & FAU & 5.63 & 7.1 \\
\hline Na-ZSM-5 (25) & Zeochem & $\mathrm{PZ}-2 / 25$ & MFI & 25 & 2.36 \\
\hline Na-ZSM-5 (40) & Zeochem & $\mathrm{PZ}-2 / 40$ & MFI & 40 & 0.50 \\
\hline Na-Beta & Zeochem & PB & BEA & 25 & 014 \\
\hline
\end{tabular}

starting sodium zeolite powder $(\sim 8 \mathrm{~g})$ is suspended in $100 \mathrm{~mL}$ of aqueous solution of $\mathrm{AgNO}_{3}$ (Alfa Aesar) for $5 \mathrm{~h}$ at $80{ }^{\circ} \mathrm{C}$. For partially and fully exchanged zeolites $\mathrm{Ag}$ concentrations are 0.01 and $0.5 \mathrm{M}$, respectively. The powders are filtered off and washed thoroughly several times with deionized water. The exchange ratios are calculated from the sodium and silver contents measured by ICP-MS (Table 2). Finally, the powders

Table 2. Cationic Composition of Silver-Exchanged Samples

\begin{tabular}{|c|c|c|c|c|c|}
\hline sample & parent zeolite & structure & $\begin{array}{c}\mathrm{Na} \\
\text { (wt \%) }\end{array}$ & $\begin{array}{c}\mathrm{Ag} \\
(\text { wt \%) }\end{array}$ & $\begin{array}{l}\text { exchange } \\
\text { ratio (\%) }\end{array}$ \\
\hline $\mathrm{NaAgX}$ & $\mathrm{NaX}$ & FAU & 5.8 & 12.8 & 32 \\
\hline $\operatorname{AgX}$ & $\mathrm{NaX}$ & FAU & $<0.1 \%$ & 34.0 & $>99$ \\
\hline $\mathrm{NaAgY}$ & $\mathrm{NaY}$ & FAU & 4.1 & 9.6 & 31 \\
\hline $\mathrm{AgY}$ & $\mathrm{NaY}$ & FAU & $<0.1 \%$ & 25.2 & $>95$ \\
\hline NaAg-PZ2-25 & Na-ZSM-5 (25) & MFI & 0.77 & 6.7 & 65 \\
\hline Ag-PZ2-25 & Na-ZSM-5 (25) & MFI & $<0.1 \%$ & 10.2 & $>99$ \\
\hline NaAg-PZ2-40 & Na-ZSM-5 (40) & MFI & 0.1 & 2.37 & 55 \\
\hline Ag-PZ2-40 & Na-ZSM-5 (25) & MFI & $<0.1 \%$ & 4.09 & $>99$ \\
\hline $\mathrm{NaAg-PB}$ & Na-Beta & Beta & - & 1.92 & 30 \\
\hline Ag-PB & Na-Beta & Beta & - & 6.1 & $>99$ \\
\hline
\end{tabular}

are treated at $400{ }^{\circ} \mathrm{C}$ in $\mathrm{N}_{2}$ flow for $4 \mathrm{~h}$ (BelPrep Vac II from BelJapan) in order to thermally stabilize the adsorbents for their applications in TSA processes.

Adsorption properties are characterized by $\mathrm{Xe}$ isotherms which were recorded at different temperatures from 288 to $338 \mathrm{~K}$. The measurements were carried out on a volumetric gas adsorption instrument Belsorp-Max (Bel Japan) with Xe (4.7 grade, Air Products) using typically $0.4 \mathrm{~g}$ of sample. Prior to measurements the samples are treated under $5 \times 10^{-5} \mathrm{~Pa}$ at $573 \mathrm{~K}$ for $12 \mathrm{~h}$. The Xe uptakes are measured at Xe pressure from $10^{-5} \mathrm{kPa}(0.1 \mathrm{ppm})$ to $100 \mathrm{kPa}$. To ensure the achievement of adsorption equilibrium during measurements at low pressure range (thus avoiding the uptake underestimation), the samples were allowed to equilibrate for periods of $300 \mathrm{~s}$ with pressure variation less than $1 \%$. For long measurement times, variation of the level of the regulated water bath (especially for measurements at $338 \mathrm{~K}$ ) and thus the change of dead volume need to be taken into account. For this, all measurements have been carried out using the high-accuracy mode of the Belsorp Max. This unique method, AFSM (Advanced Free Space Measurement), compensates the free space change in the sample cell. This is done by measuring the pressure change of a separate empty sample cell.

$\mathrm{Xe}$ NMR allows the characterization of $\mathrm{Xe}$-zeolite interactions. ${ }^{29,30}$ Before NMR experiments the samples, placed in a $10 \mathrm{~mm}$ glass tube equipped with a stopcock, were evacuated under dynamic high vacuum (less than $10^{-2} \mathrm{~Pa}$ ) at $573 \mathrm{~K}$ overnight (heating rate $30 \mathrm{~K} \cdot \mathrm{h}^{-1}$ ). Xenon was adsorbed at room temperature using a home-built apparatus. Xenon pressure was measured with a Schaefer gauge. Variable-pressure ${ }^{129} \mathrm{Xe}$ NMR spectra were recorded at $295 \mathrm{~K}$ using thermally polarized xenon 

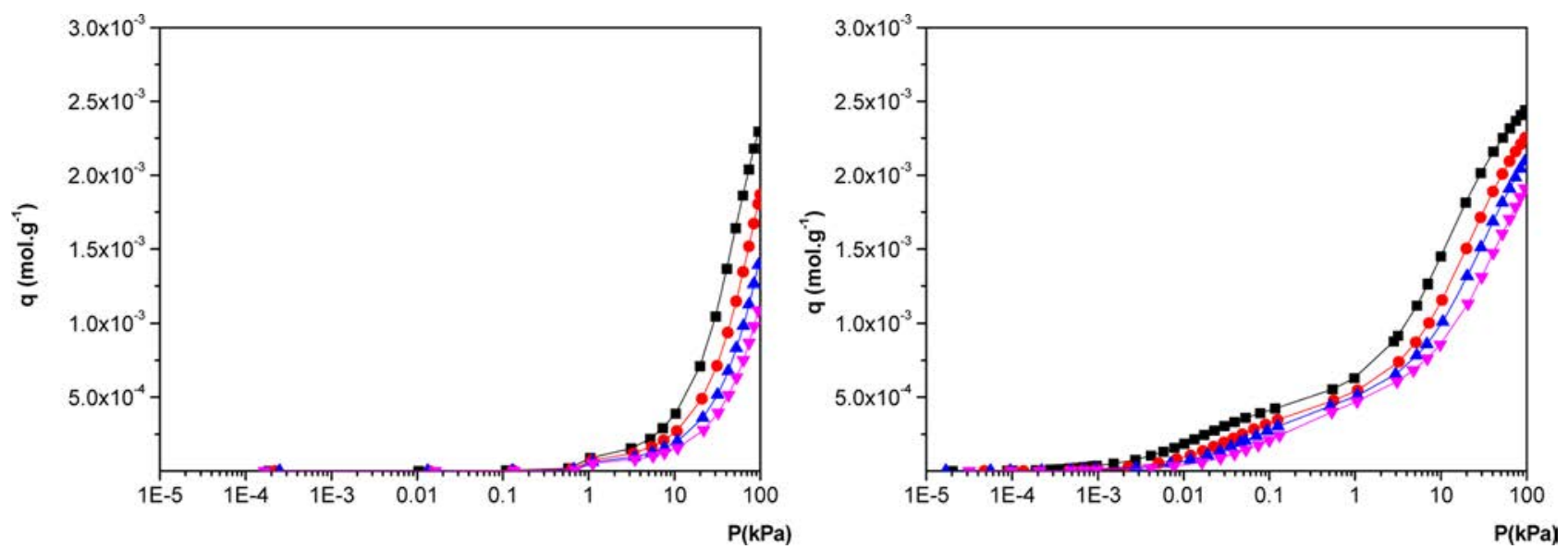

Figure 1. Xe isotherms of $\mathrm{AgNaX}$ (left) and $\mathrm{AgX}$ (right) at different temperatures, $288 \mathrm{~K}$ (square), $303 \mathrm{~K}$ (circle), $318 \mathrm{~K}$ (triangle up), and $333 \mathrm{~K}$ (triangle down).
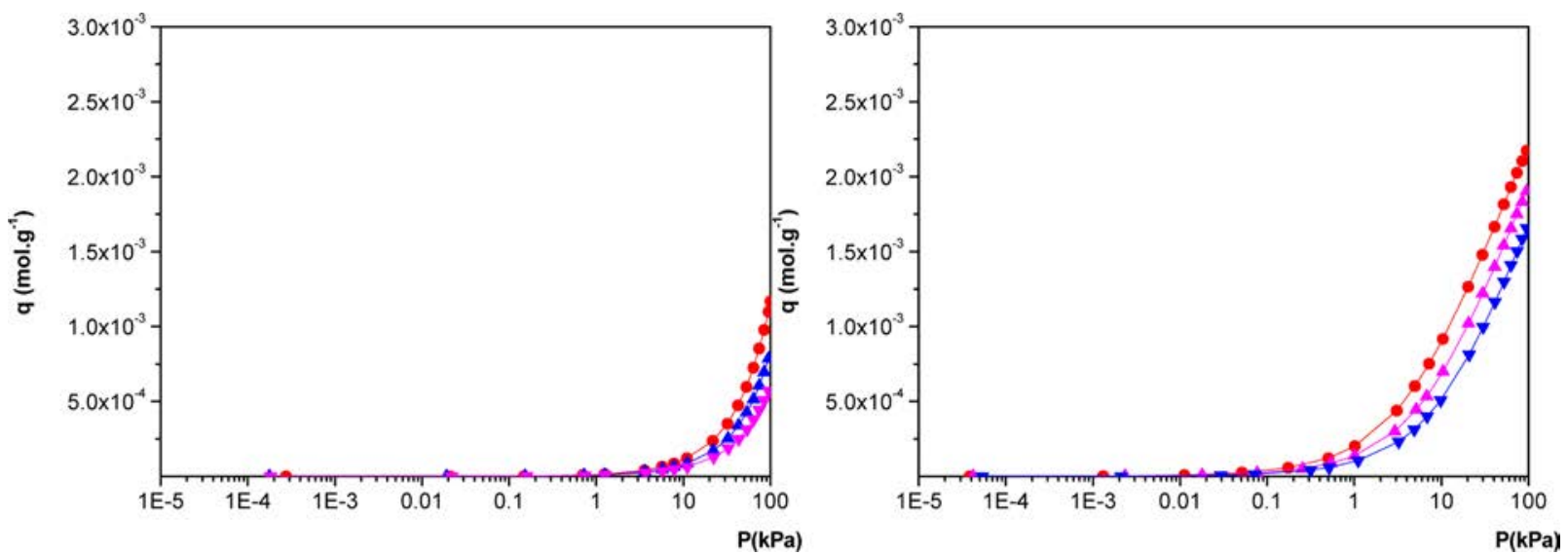

Figure 2. Xe isotherms of $\mathrm{AgNaY}$ (left) and $\mathrm{AgY}$ (right) at different temperatures, $303 \mathrm{~K}$ (circle), $318 \mathrm{~K}$ (triangle up), and $333 \mathrm{~K}$ (triangle down).
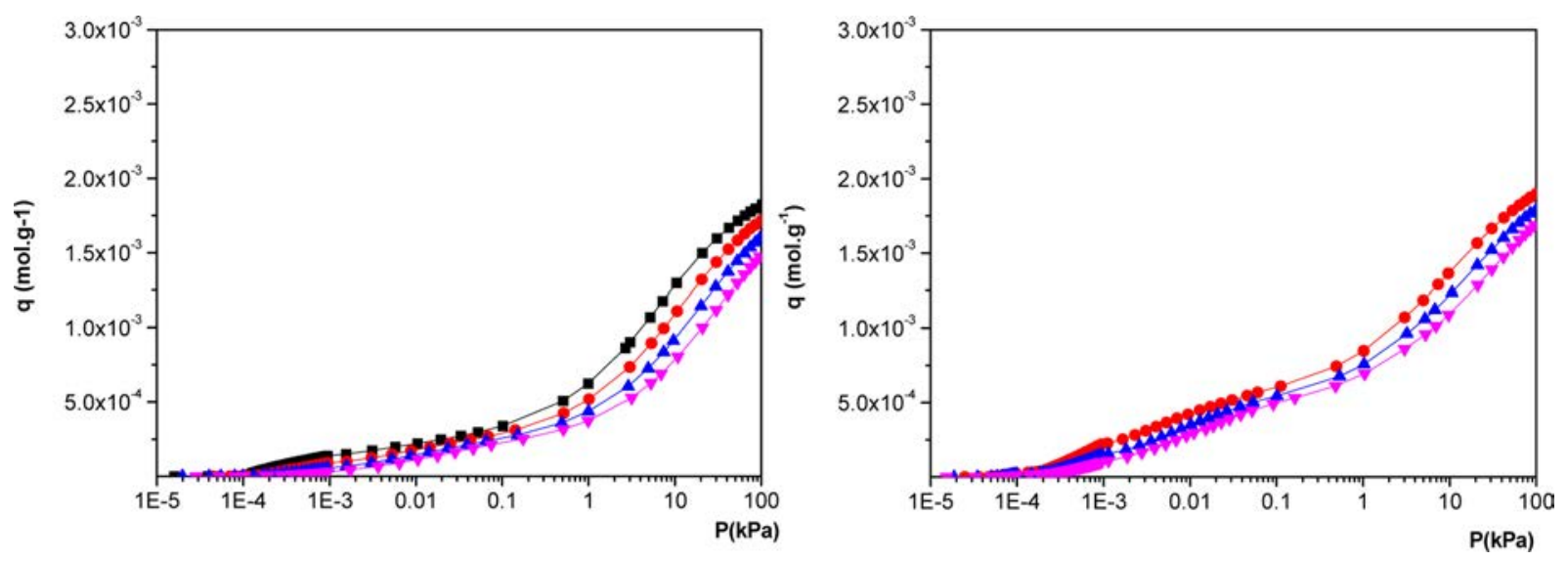

Figure 3. Xe isotherms of NaAg-PZ2-25 (left) and Ag-PZ2-25 (right) at different temperatures, $288 \mathrm{~K}$ (square), $303 \mathrm{~K}$ (circle), $318 \mathrm{~K}$ (triangle up), and $333 \mathrm{~K}$ (triangle down).

with a Bruker AMX 300 spectrometer operating at $83.02 \mathrm{MHz}$ equipped with a saddle coil probe. A $90^{\circ}$ pulse (ca. $13 \mu \mathrm{s}$ ) was used. Typically $10^{3}-10^{5}$ scans, with a repetition time of 0.5-1 s, were recorded. MAS NMR experiments have been performed using $7 \mathrm{~mm}$ Bruker probe with rotation frequency of $3 \mathrm{kHz}$. The zeolite samples with adsorbed xenon were transferred inside the glovebox into $5.6 \mathrm{~mm}$ outer diameter glass tubes and subsequently flame-sealed. The chemical shifts are referenced to that of gaseous xenon extrapolated to zero pressure $(0 \mathrm{ppm})$.

\section{RESULTS AND DISCUSSION}

Isotherms for silver-modified zeolites $\mathrm{AgX}$ (Figure 1), $\mathrm{AgY}$ (Figure 2), and AgZSM-5(25) (Figure 3) were measured at temperatures from 288 to $333 \mathrm{~K}$, whereas for Ag-PZ2-40 and Ag-PB zeolites the isotherms were measured at $303 \mathrm{~K}$ only (Figure 4). The isotherms are plotted with pressure in log scale in order to better visualize the Xe uptake over the whole pressure range, from ppm to atmospheric levels. The adsorption capacities 

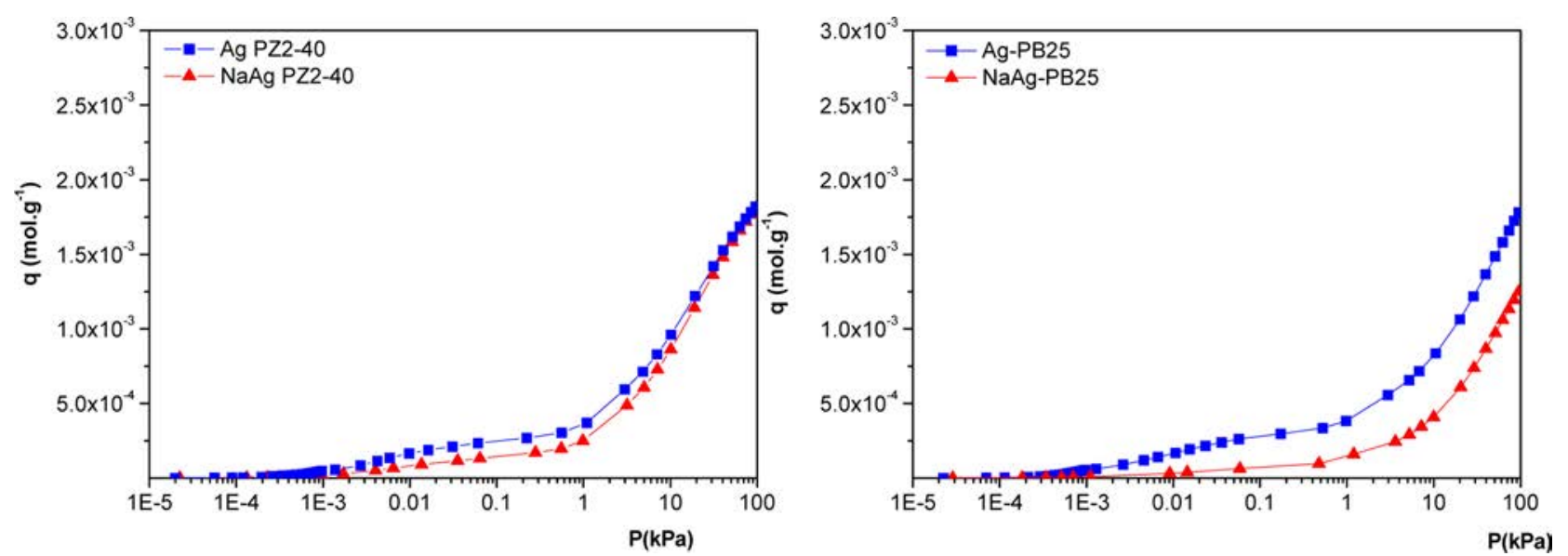

Figure 4. Xe isotherms of NaAg-PZ2-40 and Ag-PZ2-40 (left) and NaAg-PB and Ag-PB (right) at $303 \mathrm{~K}$.

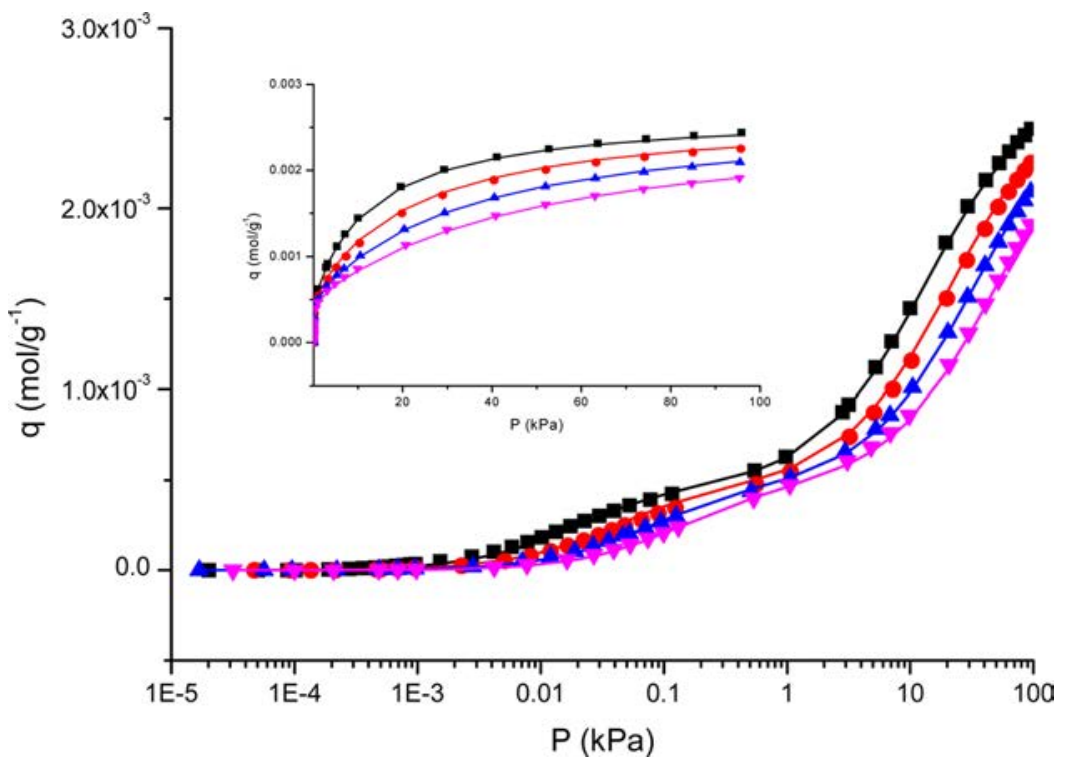

Figure 5. Modeling of AgX isotherms by the double-site model. Key: $288 \mathrm{~K}$ (square), $303 \mathrm{~K}$ (circle), $318 \mathrm{~K}$ (triangle up), and $333 \mathrm{~K}$ (triangle down). Inset: linear scale.

at $100 \mathrm{kPa}$ are relatively similar for all samples $\left(\sim 2 \times 10^{-3}\right.$ to $\left.\sim 2.5 \times 10^{-3} \mathrm{~mol} \cdot \mathrm{g}^{-1}\right)$ whereas at low pressure we can see major differences. For example, silver-modified $\mathrm{Y}$ adsorbs Xe in measurable quantities, only from $1 \mathrm{kPa}$ (Figure 2) whereas silver-modified ZSM-5 (25) zeolite begins to adsorb $\mathrm{Xe}$ at much lower pressure (Figure 3). At $10 \mathrm{~Pa}(100 \mathrm{ppm})$ and $298 \mathrm{~K}$, the xenon uptake is $5 \times 10^{-4} \mathrm{~mol} \cdot \mathrm{g}^{-1}$ for Ag-PZ2-25 against $4.3 \times 10^{-6} \mathrm{~mol} \cdot \mathrm{g}^{-1}$ for an active carbon ${ }^{13}$ and $0.16 \times$ $10^{-6} \mathrm{~mol} \cdot \mathrm{g}^{-1}$ for zeolite $5 \mathrm{~A}$. ${ }^{13}$ This corresponds to increase of more than 2-3 orders of magnitude against classical adsorbents. At first glance, we can observe two classes of isotherms profiles. The first class, $\mathrm{AgNaX}, \mathrm{AgNaY}$, and $\mathrm{AgY}$, is characterized by a single adsorption step starting between 1 and $10 \mathrm{kPa}$. In contrast, the isotherms of the second class reveal double adsorption steps, at low pressure from $10^{-3}$ to $10^{-1} \mathrm{kPa}$ and a second at higher pressure. This second class comprises AgX, NaAg-PZ2-25, Ag-PZ2-25, NaAg-PZ2-40, Ag-PZ2-40, $\mathrm{NaAg}-\mathrm{PB}$, and Ag-PB.

The isotherm modeling allows the estimation of intrinsic parameters of adsorbents such as the adsorption heats and the number of adsorption sites. The estimation of parameters is carried out by multinonlinear regression on a Langmuir extended model. The model is built by the sum of two independent Langmuir isotherms in order to accommodate the double adsorption steps experimentally observed. Hence, the model involves two adsorption sites, (1) and (2), which are each characterized by a number of adsorption sites $\left(N_{1}\right)$ and $\left(N_{2}\right)$, and by equilibrium constants, $K_{1}$ and $K_{2}$. Surface heterogeneity parameter, $\alpha$, is introduced in the van't Hoff law, as a linear variation of the heat of adsorption with the surface coverage to account for surface heterogeneity (eq 2) also referred as the Tempkin adsorption isotherm. ${ }^{31}$ Hence, for each sample, six parameters shall be estimated.

$$
q=q_{1}+q_{2}=N_{1} \frac{K_{1} \cdot P_{\mathrm{Xe}}}{1+K_{1} \cdot P_{\mathrm{Xe}}}+N_{2} \frac{K_{2} \cdot P_{\mathrm{Xe}}}{1+K_{2} \cdot P_{\mathrm{Xe}}}
$$

where $q$ is the adsorbed xenon amount $\left(\mathrm{mol} \cdot \mathrm{g}^{-1}\right), P_{\mathrm{Xe}}$ stands for Xe pressure $(\mathrm{Pa})$, and $K_{1}(T)$ and $K_{2}(T)$ are the equilibrium constants for the two sites which can be expressed according the modified van't Hoff law

$$
\ln K_{i}(T)=-\frac{\left(\Delta H^{\circ}-\alpha_{i} \theta_{\mathrm{Xe}}\right)}{R T}+\frac{\Delta S^{\circ}}{R}
$$


Table 3. Estimated Parameters of the Double-Site Model Obtained from Multilinear Regressions ${ }^{a}$

\begin{tabular}{|c|c|c|c|c|c|c|c|c|}
\hline & $\begin{array}{c}-\Delta H_{2} \\
\left(\mathrm{~kJ} \cdot \mathrm{mol}^{-1}\right)\end{array}$ & $\begin{array}{c}\Delta S_{2} \\
\left(\mathrm{~J} \cdot \mathrm{mol}^{-1} \mathrm{~K}^{-1}\right)\end{array}$ & $\begin{array}{c}\alpha_{2} \\
\left(\mathrm{~kJ} \cdot \mathrm{mol}^{-1}\right)\end{array}$ & $N_{2}\left(\mathrm{~mol} \cdot \mathrm{g}^{-1}\right)$ & $\begin{array}{c}-\Delta H_{1} \\
\left(\mathrm{~kJ} \cdot \mathrm{mol}^{-1}\right)\end{array}$ & $\begin{array}{c}\Delta S_{1} \\
\left(\mathrm{~J} \cdot \mathrm{mol}^{-1} \mathrm{~K}^{-1}\right)\end{array}$ & $\begin{array}{c}\alpha_{1} \\
\left(\mathrm{~kJ} \cdot \mathrm{mol}^{-1}\right)\end{array}$ & $N_{1}\left(\mathrm{~mol} \cdot \mathrm{g}^{-1}\right)$ \\
\hline $\mathrm{AgNaX}$ & - & - & - & - & $20.4 \pm 1$ & $74.0 \pm 8$ & 0 & $(5.6 \pm 0.4) \times 10^{-3}$ \\
\hline $\mathrm{AgX}$ & $35.4 \pm 2$ & $51.6 \pm 5$ & 0 & $(4.8 \pm 0.1) \times 10^{-4}$ & $23.9 \pm 1$ & $66.1 \pm 3$ & 0 & $(2.2 \pm 0.1) \times 10^{-3}$ \\
\hline $\mathrm{AgNaY}$ & - & - & - & - & $18.1 \pm 0.3$ & $69.2 \pm 5$ & $-3.6 \pm 0.2$ & $(3.5 \pm 0.3) \times 10^{-3}$ \\
\hline $\mathrm{AgY}$ & - & - & - & - & $26.6 \pm 0.3$ & $73.9 \pm 7$ & $7.5 \pm 2$ & $(4.2 . \pm 0.4) \times 10^{-3}$ \\
\hline NaAg-PZ2-25 & $48.2 \pm 3$ & $67.0 \pm 7$ & $3.7 \pm 1$ & $(2.8 \pm 0.1) \times 10^{-4}$ & $31.1 \pm 0.5$ & $76.1 \pm 8$ & $4.4 \pm 0.5$ & $(1.8 \pm 0.1) \times 10^{-3}$ \\
\hline Ag-PZ2-25 & $39.9 \pm 2$ & $36.6 \pm 2$ & $4.1 \pm 0.7$ & $(5.7 \pm 0.5) \times 10^{-4}$ & $34.4 \pm 2$ & $78.0 \pm 15$ & $6.1 \pm 1.1$ & $(1.6 \pm 0.1) \times 10^{-3}$ \\
\hline
\end{tabular}

${ }^{a}$ The parameters denoted with 2 as index correspond to the strongest adsorption site (2) whereas indiex 1 refers to the weakest site (1).

Table 4. Silver Loading, Estimated Number of Adsorption Sites, and Equilibrium Constants for the Strong and Weak Sites at $303 \mathrm{~K}$

\begin{tabular}{|c|c|c|c|c|c|}
\hline & Ag loading $\left(\mathrm{mol} \cdot \mathrm{g}^{-1}\right)$ & $N_{2}\left(\mathrm{~mol} \cdot \mathrm{g}^{-1}\right)$ & $K_{2}\left(\mathrm{kPa}^{-1}\right)$ & $N_{1}\left(\mathrm{~mol} \cdot \mathrm{g}^{-1}\right)$ & $K_{1}\left(\mathrm{kPa}^{-1}\right)$ \\
\hline $\mathrm{NaAg}-\mathrm{PZ2}-25$ & $6.21 \times 10^{-4}$ & $2.8 \times 10^{-4}$ & 643 & $1.8 \times 10^{-3}$ & 0.2 \\
\hline Ag-PZ2-25 & $9.46 \times 10^{-4}$ & $5.7 \times 10^{-4}$ & 925 & $1.6 \times 10^{-3}$ & 0.8 \\
\hline NaAg-PZ2-40 & $2.20 \times 10^{-4}$ & $1.6 \times 10^{-4}$ & 103 & $1.9 \times 10^{-3}$ & 0.06 \\
\hline Ag-PZ2-40 & $3.79 \times 10^{-4}$ & $2.6 \times 10^{-4}$ & 181 & $1.8 \times 10^{-3}$ & 0.06 \\
\hline NaAg-PB & $1.78 \times 10^{-4}$ & $1.2 \times 10^{-4}$ & 19 & $1.7 \times 10^{-3}$ & 0.02 \\
\hline Ag-PB & $5.65 \times 10^{-4}$ & $3.3 \times 10^{-4}$ & 113 & $1.4 \times 10^{-3}$ & 0.04 \\
\hline $\operatorname{AgX}$ & $31.53 \times 10^{-4}$ & $4.8 \times 10^{-4}$ & 26 & $2.2 \times 10^{-3}$ & 0.05 \\
\hline
\end{tabular}

where $\Delta S^{\circ}$ is the standard adsorption entropy and $\Delta H^{\circ}$ is the standard adsorption enthalpy and where $\alpha_{\mathrm{i}}(\mathrm{kJ} / \mathrm{mol})$ describes the change of the heat of adsorption as a function of the surface coverage of $\mathrm{Xe}\left(\theta_{\mathrm{Xe}}\right)$.

As an example, the result of the modeling of the Xe isotherm on AgX can be observed in Figure 5. The model describes very well the experimental adsorption isotherms at both low and atmospheric pressure. A single-site model does not describe adequately the isotherms over the entire pressure range for samples belonging to the second class. The estimated parameters are reported in Table 3. In some cases the data could not be described adequately by a pure Langmuir isotherm. In that case the Tempkin isotherm was used with nonzero values for $\alpha_{i}$. In that case eq 1 was not the only isotherm that fitted the data. The surface heterogeneity could also be accounted for by assuming the heat of adsorption dependence on the $\mathrm{Xe}$ coverage.

No strong binary correlation coefficients were observed between the parameters, except in the cases where the isotherms are still linear at high pressure. In these cases the number of active sites cannot be estimated accurately and a strong parameter correlation is found with the adsorption rate constant.

The enthalpy and entropy of adsorption parameters were not estimated for silver-modified ZSM-5 (40) and silver-modified Beta because the isotherms were recorded at only one temperature. For $\mathrm{AgNaX}, \mathrm{AgNaY}$, and $\mathrm{AgY}$, the number of strongest adsorption sites (2) were set at nil because very good fits were obtained with a single-site model. For adsorbents possessing both adsorption sites (AgX, NaAg-PZ2-25, and Ag-PZ2-25), the number of strong sites $\left(\mathrm{N}_{2}\right)$ is $4-8$-fold smaller than the number of weak sites $\left(N_{1}\right)$. The values of $-\Delta H_{1}$ are ranging from 20 to $35 \mathrm{~kJ} \cdot \mathrm{mol}^{-1}$ whereas for $-\Delta H_{2}$ values comprise between 35 and $50 \mathrm{~kJ} \cdot \mathrm{mol}^{-1}$. As we can expect, the adsorption enthalpies of the strongest adsorption sites (2) are larger than those of the weak adsorption sites (1). For AgY possessing weak adsorption sites, we measured a heat of adsorption of $-26.6 \mathrm{~kJ} \cdot \mathrm{mol}^{-1}$ against $-31 \mathrm{~kJ} \cdot \mathrm{mol}^{-1}$ previously reported. ${ }^{13} \mathrm{~A}$ comparison with literature data can hardly be carried out for the strong adsorption sites, since they were never evidenced until this study. Nevertheless, we can note that estimated $-\Delta H_{2}$ values are closer to the value measured by chromatography for Ag-ETS-10 $\left(-52.5 \mathrm{~kJ} \cdot \mathrm{mol}^{-1}\right){ }^{21}$

For the class of adsorbents exhibiting strong sites, parameter estimates of isotherms at $303 \mathrm{~K}$ are reported in Table 4. The equilibrium constant $K_{2}$ of Ag-PZ2-25 is about 50-fold larger than that of $\mathrm{AgX}$, although the silver content is about one-third lower. The number of strong sites $\left(\mathrm{N}_{2}\right)$ is plotted as function of the silver loading of the adsorbents, regardless of the nature and structure of the Ag for Pentasil zeolite type (Figure 6). We can

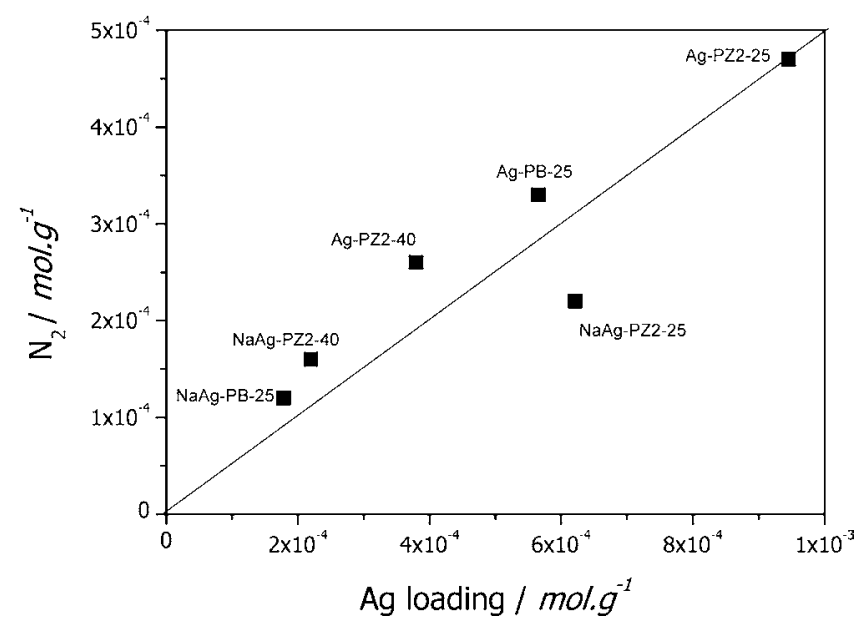

Figure 6. Plot of the number of strong adsorption sites $\left(N_{2}\right)$ as a function of the amount of silver loading in Pentasil-type zeolites.

observe a clear linear tendency. Approximately, there is a ratio of 2 moles of $\mathrm{Ag}$ for 1 mole of strong sites. We note, however, a deviation for NaAg-PZ2-25 in the Pentasil series whereas AgX completely falls out of the linear trend (see Supporting Information).

The variable-pressure ${ }^{129} \mathrm{Xe}$ NMR spectra of xenon adsorbed on silver-modified faujasites and silver-modified ZSM-5(25) are shown in Figures 7 and 8, respectively. At low pressure, the spectra exhibit broad asymmetric lines with negative chemical 

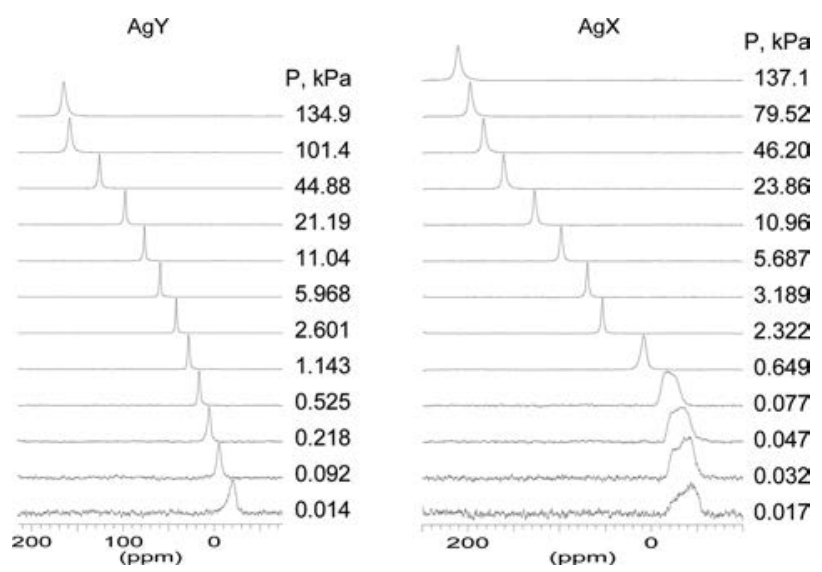

Figure 7. ${ }^{129} \mathrm{Xe}$ NMR spectra at $298 \mathrm{~K}$ as function of Xe pressure: $\mathrm{AgY}$ (left), AgX (right).
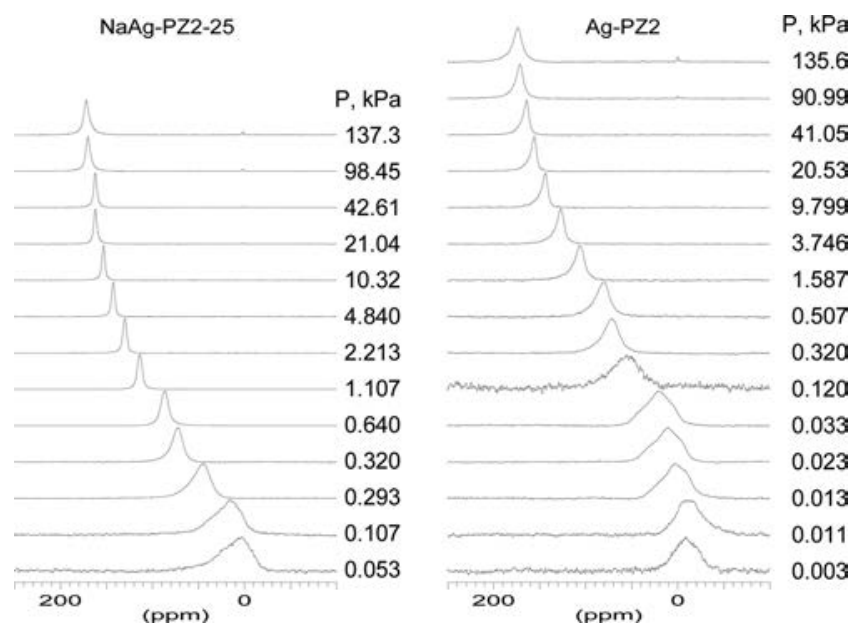

Figure $8 .{ }^{129} \mathrm{Xe}$ NMR spectra at $298 \mathrm{~K}$ as a function of Xe pressure: NaAg-PZ2-25 (left), Ag-PZ2-25 (right).

shifts. As xenon pressure increases, the lines shift to low field and become narrower and more symmetrical. The line width further increases at high pressures. The chemical shifts of xenon adsorbed in zeolites depend on the size and shape of their pores, chemical composition of the surface, and nature and oxidation state of cations as well as on the presence of other adsorbates and xenon pressure. ${ }^{29,30}$ In general, chemical shift of xenon increases with the decrease of the size of the voids it explores, and the typical values of the chemical shift of xenon in alkaline forms of zeolites at low xenon loadings are in the range of 50-200 ppm. Thus, the negative values of chemical shifts observed for Ag forms of zeolites are caused by strong interaction of xenon with silver species as already reported in the literature. ${ }^{16,19}$

To elucidate the origin of the large line width of the signals at low Xe pressure, we performed magic angle spinning (MAS) experiments for $\mathrm{AgX}$ and Ag-PZ2-25. The results prove that the large signals observed in the case of $\mathrm{AgX}$ are due to the presence of several overlapping isotropic signals, since they are not changing under magic angle spinning. They may originate from a distribution of $\mathrm{Ag}$ species in $\mathrm{AgX}$. Since the interaction of xenon with these different species is strong, it is not averaged by exchange and several distinct signals are observed. On the contrary, in the case of Ag-PZ2-25, the broad line observed in static experiments becomes narrow under MAS conditions, revealing the anisotropic nature of the line (Figure 9). Such anisotropic line has already been observed in MFI structure, when the mobility of xenon was diminished by high xenon loadings or low temperature. ${ }^{32}$ In our case, the mobility of xenon atoms may be restricted by their interaction with silver particles.

For a series of zeolites, the NMR shifts are plotted as a function of the Xe uptake (Figure 10). As expected for a sodium (silver-

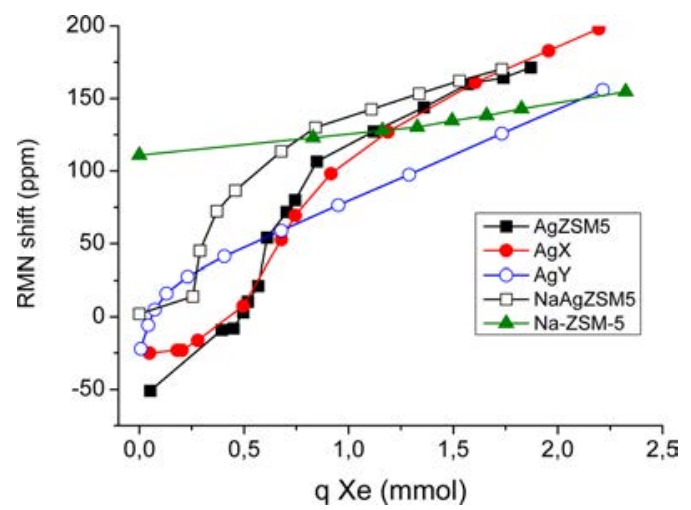

Figure 10. Plot of the Xe NMR shift as a function of the Xe adsorbed.

freezeolite), we can observe a monotonic increase of the NMR shift as a function of pressure. For AgY, which does not possess
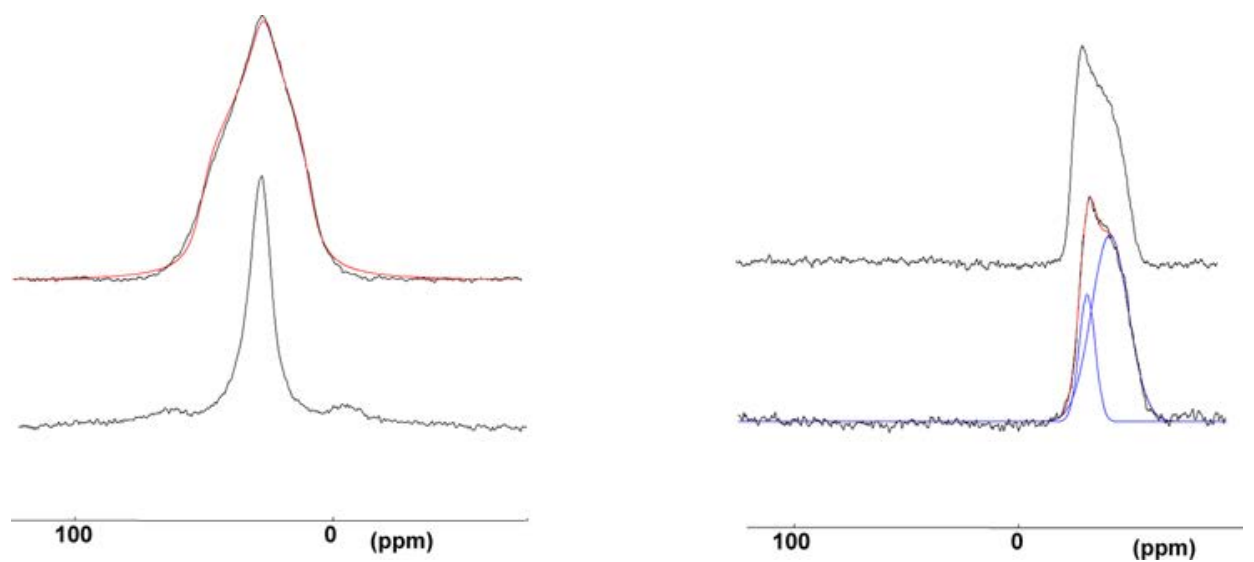

Figure 9. Static (top) and MAS (bottom) NMR spectra of Ag-PZ2-25 (left) and AgX (right). Experimental (black) and simulated (colored) signals. Anisotropy parameters of Ag-PZ2-25 line: $\Delta \delta=22.8 \mathrm{ppm} ; \eta=0.82$. Deconvolution of AgX line: $\delta_{1}=-22.1 \mathrm{ppm}, \delta_{2}=-36.6 \mathrm{ppm}$. 
strong adsorption sites (2), the shift is increasing sharply with the $\mathrm{Xe}$ loading. At higher loading the trend becomes linear. In contrast, for AgX, NaAg-PZ2-25, and Ag-PZ2-25, which possess strong adsorption sites, we can observe a S-shaped profile. The curve can be divided in three parts. At very low Xe uptakes, we can assume the existence of a plateau. Then, the NMR signals shift with pressure and finally the dependence becomes linear at loading close to saturation. Interestingly, the xenon loadings at which the signal shifts the most (after the plateau) correspond to the number of strong sites $\left(\mathrm{N}_{2}\right)$. For NaAg-PZ2-25, the number of strong sites $\left(N_{2}\right)$ is $0.22 \times 10^{-3} \mathrm{~mol} \cdot \mathrm{g}^{-1}$ and we can see that the signal starts an abrupt shift at about $0.25 \times 10^{-3} \mathrm{~mol} \cdot \mathrm{g}^{-1}$ of adsorbed Xe. Similarly, for Ag-PZ2-25 and AgX which possess about $0.47 \times 10^{-3} \mathrm{~mol} \cdot \mathrm{g}^{-1}$ of strong sites, the slope changes at about $0.5 \times 10^{-3} \mathrm{~mol} \cdot \mathrm{g}^{-1}$ of adsorbed Xe.

The observed changes of NMR shifts as a function of Xe uptake are fully consistent with the literature data on silver faujasite. For silver-modified Y zeolites, the shape of the curves is independent of the $\mathrm{Ag}$ loading and strong sites cannot be observed. ${ }^{24}$ On the other hand, the S-shape profile is present for dehydrated and oxidized AgX zeolites which also shows the largest Xe uptake at low pressure. ${ }^{16}$ Gédéon et al. have shown a correlation between Xe adsorption isotherms and Xe NMR signals. ${ }^{16}$ Here, we show that Xe NMR could be used as a quantitative method for the characterization of the strength and the number of strong $\mathrm{Xe}$ adsorption sites on silver-modified zeolites.

The results of this study shed light on the main factors which drive xenon adsorption. The data in Table 4 suggest that adsorption performances at very low pressure do not depend on porous features of zeolites. Indeed, AgX and AgY which exhibit the same pore structure (FAU) show very different adsorption properties. On the other hand, the silver content appears as a main parameter (Figure 6). Interestingly, the number of strong adsorption sites $N_{2}$ is always slightly smaller than the silver loading (Table 4). This may suggest that all $\mathrm{Ag}$ atoms are not accessible to $\mathrm{Xe}$ and that the dispersion at silver isoloading may represent a cutoff between strong and weak adsorption sites. The structural characterization of strong adsorption sites will be reported in a forthcoming paper.

\section{CONCLUSIONS}

Number and strength of adsorption sites in silver-modified zeolites were estimated from isotherm modeling. The zeolites may present one or two distinct adsorption sites depending on the nature of the zeolite type and on silver loadings. The strongest adsorption sites are characterized by isosteric heat of adsorption in the order of -35 to $-50 \mathrm{~kJ} \cdot \mathrm{mol}^{-1}$. We observe a linear 2:1 correlation between the total amount of silver and the number of strong sites for Pentasil-type zeolithes. The structural characterization and the nature of the adsorption sites will be reported in a detailed separate study. The highest concentration of strong sites is found for fully silver exchanged ZSM-5 which presents the largest silver content for Pentasiltype zeolite. Correlations were established between $\mathrm{Xe}$ adsorption isotherms and ${ }^{129} \mathrm{Xe}$ NMR signals. Here we show Xe NMR could be used as a quantitative method for the characterization of the strength and of the number of strong $\mathrm{Xe}$ adsorption sites on silver-exchanged zeolites. The numbers of strong adsorption sites responsible for the Xe adsorption at 10-1000 ppm can be determined by the length of the plateau observed at low Xe uptake. The equilibrium constant $K_{2}$ of Ag-PZ2-25 is about 50 larger than the one of $\mathrm{AgX}$, although the silver content is about one-third lower. In practice, our findings give guidelines for the discovery and optimization of silverloaded zeolites for the capture of Xe at ppm levels. Finally, by using a Ag-ZSM-5 instead of an active carbon, the size of the adsorbent bed could be reduced by at least 1 order of magnitude for atmospheric xenon capture.

\section{ASSOCIATED CONTENT}

S Supporting Information

Plot of the number of strong adsorption sites $\left(N_{2}\right)$ as a function of the amount of silver loading. This material is available free of charge via the Internet at http://pubs.acs.org.

\section{AUTHOR INFORMATION}

\section{Corresponding Author}

Tel.: +33472 445365. E-mail: david.farrusseng@ircelyon. univ-lyon 1.fr.

\section{Notes}

The authors declare no competing financial interest.

\section{ACKNOWLEDGMENTS}

We thank IRCELYON Scientific services for sample characterization. We also thank Dr. R. Dez (Apollo Instruments) for advice on measurements.

\section{REFERENCES}

(1) Dubasov, Y. V.; Popov, Y. S.; Prelovskii, V. V.; Donets, A. Y.; Kazarinov, N. M.; Mishurinskii, V. V.; Popov, V. Y.; Rykov, Y. M.; Skirda, N. V. The APIKC-01 Automatic Facility for Measuring Concentrations of Radioactive Xenon Isotopes in the Atmosphere. Instrum. Exp. Tech. 2005, 48, 373-379.

(2) Hammarlund, N. The Krypton and Xenon Markets up to the Year 2000. Nucl. Instrum. Methods A 1992, 316, 83-87.

(3) Auer, M.; Taffary, T. Intercomparison Experiments of Systems for the Measurement of Xenon Radionuclides in the Amosphere. Appl. Radiat. Isot. 2004, 60, 863-877.

(4) Bowyer, T. W.; Abel, K. H.; Hubbard, C. W.; McKinnon, A. D.; Panisko, M. E.; Perkins, R. W.; Reeder, P. L.; Thompson, R. C.; Warner, R. A. Automated Separation and Measurement of Radioxenon for the Comprehensive Test Ban Treaty. J. Radioanal. Nucl. Chem. 1998, 235, 77-81.

(5) Prelovskii, V. V.; Kazarinov, N. M.; Donets, A. Y.; Popov, V. Y.; Popov, I. Y.; Skirda, N. V. The ARIX-03F Mobile Semiautomatic Facility for Measuring Low Concentrations of Radioactive Xenon Isotopes in Air and Subsoil. Gas. Instrum. Exp. Tech. 2007, 50, 393397.

(6) Ringbom, A.; Larson, T.; Axelsson, A.; Elmgren, K.; Johansson, C. SAUNA - a System for Automatic Sampling, Processing, and Analysis of Radioactive Xenon. Nucl. Instrum. Methods A 2003, 508, 542-553.

(7) Stocki, T. J.; Taffary, T. Automated Radioxenon Monitoring for the Comprehensive Nuclear-Test-Ban Treaty in Two Distinctive locations: Ottawa and Tahiti. J. Environ. Radioact. 2005, 80, 305-326.

(8) Fontaine, J.-P.; Pointurier, F.; Blanchard, X.; Taffary, T. Atmospheric Xenon Radioactive Isotope Monitoring. J. Environ. Radioact. 2004, 72, 129-135.

(9) Barrer, R. M.; Davies, J. M. Sorption in Decationated Zeolites. I. Gases in Hydrogen-Chabazite. Proc. R. Soc. London, Ser. A 1970, 320, 289-308.

(10) Barrer, R. M.; Papadopoulos, R. Sorption of Krypton and Xenon in Zeolites at High Pressures and Temperatures. I. Chabazite. Proc. $R$. Soc. London, Ser. A 1972, 326, 315-330.

(11) Barrer, R. M.; Papadopoulos, R.; Ramsay, J. D. F. Sorption of Krypton and Xenon in Zeolites at High Pressures and Temperatures. II. Comparison and Analysis. Proc. R. Soc. London, Ser. A 1972, 326, 331-345. 
(12) Munakata, K.; Fukumatsu, T.; Yamatsuki, S.; Tanaka, K.; Nishikawa, M. Adsorption Equilibria of Krypton, Xenon, Nitrogen and Their Mixtures on Molecular Sieve 5A and Activated Charcoal. J. Nucl. Sci. Technol. 1999, 36, 818-829.

(13) Watermann, J.; Boddenberg, B. Isosteric Heats of Adsorption of Xenon in Silver-Echanged Y Zeolites. Zeolites 1993, 13, 427-429.

(14) Saxton, C. G.; Kruth, A.; Castro, M.; Wright, P. A.; Howe, R. F. Xenon Adsorption in Synthetic Chabazite. Zeolites. Microporous Mesoporous Mater. 2010, 129, 68-73.

(15) Fraissard, J.; Gedeon, A.; Chen, Q.; Ito, T. Xenon-129 NMR Study of Intra- and Inter- Crystallite Diffusion of Cations in Faujasite Zeolites. Stud. Surf. Sci. Catal. 1991, 69, 461.

(16) Gedeon, A.; Burmeister, R.; Grosse, R.; Boddenberg, B.; Fraissard, J. 129 NMR for the Study of Oxidised and Reduced AgX Zeolites. Chem. Phys. Lett. 1991, 179, 191-194.

(17) Grosse, R.; Gedeon, A.; Watermann, J.; Fraissard, J.; Boddenberg, B. Adsorption and 129Xe NMR of Xenon in SilverExchanged Y Zeolites: Application to the Location of Silver Cations. Zeolites 1992, 12, 909-915.

(18) Grosse, R.; Burmeister, R.; Boddenberg, B.; Gedeon, A.; Fraissard, J. Adsorption and 129Xe NMR of Xenon in SilverExchanged Y Zeolites. J. Phys. Chem. 1991, 95, 2443-2447.

(19) Gedeon, A.; Fraissard, J. 129 NMR Study of AgX, CuX, CdX and $\mathrm{ZnX}$ Zeolites. Comparaison Study of nd10 Element-Xe Interactions. Chem. Phys. Lett. 1994, 219, 440-444.

(20) Munakata, K.; Kanjo, S.; Yamastuki, S.; Koga, A.; Ianovski, D. Adsorption of Noble Gases on Silver-Mordenite. J. Nucl. Sci. Technol. 2003, 40, 695-697.

(21) Kuznicki, S. M.; Anson, A.; Koenig, A.; Kuznicki, T. M.; Haastrup, T. Xenon Adsorption on Modified ETS-10. J. Phys. Chem. C 2007, 111, 1560-1562.

(22) Nguyen, H. G.; Konya, G.; Eyring, E. M.; Hunter, D. B.; Truong, T. N. Theoretical Study on the Interaction between Xenon and Positively Charged Silver Clusters in Gas Phase and on the (001) Chabazite Surface. J. Phys. Chem. C 2009, 113, 12818-12825.

(23) Kazuiko, F.; Akihiro, N.; Tatsuya, H.; Yasushige, K.; Toshinori, M.; Hiroe, T. Patent WO2010021127.

(24) Grosse, R.; Gedeon, A.; Watermann, J.; Fraissard, J.; Boddenberg, B. Adsorption and 129Xe NMR of Xenon in SilverExchanged Y Zeolites: Application to the Location of Silver Cations. Zeolites 1992, 12, 909-915.

(25) Grosse, R.; Burmeister, R.; Boddenberg, B.; Gedeon, A.; Fraissard, J. Adsorption and 129Xe NMR of Xenon in SilverExchanged Y Zeolites. J. Phys. Chem. 1991, 95, 2443-2447.

(26) Freitag, A.; van Wüllen, C.; Staemmler, V. An ab initio Study of the Chemical Bond and the 129Xe NMR Chemical Shifts in M+-Xe Compounds, $\mathrm{M}=\mathrm{Li}, \mathrm{Na}, \mathrm{K}, \mathrm{Cu}, \mathrm{Ag}$. Chem. Phys. 1995, 192, 267-280.

(27) Moudrakovski, I.; Ratcliffe, C. I.; Ripmeester, J. A. 129Xe NMR Study of Adsorption and Dynamics of Xenon in AgA Zeolite. J. Am. Chem. Soc. 1998, 120, 3123-3132.

(28) Jameson, C. J.; Lim, H.-M. J. Distribution and 129Xe NMR Chemical Shifts of Xenon Clusters in the Alpha Cages of Zeolite AgA. Chem. Phys. 1997, 107, 4373-4383.

(29) Fraissard, J.; Ito, T. 129Xe NMR Study of Adsorbed Xenon: A New Method for Studying Zeolites and Metal-Zeolites. Zeolites 1988, $8,350-361$.

(30) Springuel-Huet, M. A.; Bonardet, J.-L.; Gedeon, A.; Fraissard. 129Xe NMR Overview of Xenon Physisorbed in Porous Solid. J. Magn. Reson. Chem. 1999, 37, S1-S13.

(31) Masel, R. I. Principles of Adsorption and Reaction on Solid Surfaces; Wiley: New York, 1996.

(32) Jameson, C. J.; Jameson, A. K.; Gerald, R. E., II; Lim, H.-M. Anisotropic Xe Chemical Shifts in Zeolites. J. Phys. Chem. B 1997, 101, 8418-8437. 